\title{
Regarding Constituents of Subjective-Self
}

\author{
Jinchang Wang \\ Stockton University, New Jersey, USA
}

\begin{abstract}
The kernel of human consciousness is self-consciousness. We in this article explore the issue about what subjective-self is composed of. A distinctive feature of "I" is uniqueness or un-duplicableness. By critically reviewing a few thought experiments, we reason that subjective-self must be composed of more than a blob of brain cells which are sophisticated enough to think reflexively and a bundle of memories and perceptions. There must be a third constituent for the existence of "I". We put forward two hypotheses for the third constituent. One is that it is something like dark matters or dark energy. Another is that it is something in the higher dimensional space. A person would lose his self-consciousness after death since the death takes away the two necessary constituents of subjective-self, his brain and memories. Where the third constituent would go after death remains a mystery.
\end{abstract}

Keywords: subjective self, self-consciousness, self-identity

\section{Introduction}

Subjective-self is the "self” from the standpoint of the first person "I”. A person's subjective-self is his/her ego viewed as the conscious mind that he/she considers his/her "self". Self-identity refers to the self-recognition from the standpoint of the first person who is the substrate of subjective-self. Every person has one subjective self-identity, except in cases of some mental diseases such as dissociate identity disorder. It is his/her inner "I" from which he/she recognizes and interacts with the outside world.

Self-awareness or self-consciousness refers to awareness of the existence of the subjective-self. It recognizes the subjective-self as an individual separate and different from the anything else around. The essentials of self-awareness or self-consciousness are: "I am aware of the existence of myself", "I am different from anything else in the world", and, "If I die, then my self and the world around me will disappear forever." Recognizing existence of self requires the intelligent capability of introspection and reflection which are possessed only by human beings.

"Self-identity" is subjective, while "identity" is objective. My identity is who I am from the other people's standpoints, including my name, age, nationality, marriage, family, parents, occupation, home address, SS number, driver's license number, my photo, finger prints, education, voice, etc. While my self-identity is who I am from my own standpoint, including my own thoughts and feelings which no one would know if I did not tell them, my own death sometime in future, and my own fear of death that results from knowing that both myself and the world around me will vanish forever when I die.

Kurzweil (2002) pointed out, "The essence of consciousness is subjective experience, not objective correlates of that experience.” And, further,

Jinchang Wang, Ph.D., Professor, Stockton University, New Jersey, USA. 
When people speak of consciousness they often slip into considerations of behavioral and neurological correlates of consciousness (for example, whether or not an entity can be self-reflective). But these are third-person (objective) issues and do not represent what David (Chalmers) calls the "hard question” of consciousness: how can matter (the brain) lead to something as apparently immaterial as consciousness? (Kurzweil, 2005)

Subjective-self, self-identity, self-awareness, and self-consciousness co-exist and are mutually dependent. It is not possible to have something with self-awareness and self-consciousness but without a subjective-self because otherwise self-awareness would have nothing to be aware of. It is not possible to have something with subjective-self and self-identity but with no self-consciousness since existence of subjective-self and self-identity is dependent on the recognition of self-awareness and self-consciousness.

Self-awareness implies the knowledge and therefore the fear of death. Becker agreed with Freud and convincingly argued in his The Denial of Death that "the main thesis of this book is that it does much more than that: the idea of death, the fear of it, haunts the human animal like nothing else; it is a mainspring of human activity - activity designed largely to avoid the fatality of death, to overcome it by denying in some way that it is the final destiny for man” (1973, p. xvii). He further argued that it's self-awareness that enables humans to have the idea of death, the fear of it, and dilemma in living and death. "The knowledge of death is reflective and conceptual, and animals are spared it." "Man is literally split in two: he has an awareness of his own splendid uniqueness in that he sticks out of nature with a towering majesty, and yet he goes back into the ground a few feet in order to blindly and dumbly to rot and disappear forever. It is a terrifying dilemma to be in and to have to live with” (1973, pp. 26-27). Indeed, self-consciousness is a key, or the key, for humans to be distinctive from the lower animals.

Kant summarized the crucial issues of humanity into three questions: "What can I know? What should I do? What can I hope for?” (Precht, 2009) Those “I’s” referred to subjective I's.

The human mind is subtle and mysterious; it looks beyond the world our knowledge has covered. Physicist Penrose once admitted, "I do my best to express, in a dispassionate way, my scientific reasons for disbelieving this perception, and arguing that conscious minds can find no home within our present-day scientific world-view” (Penrose, 1999).

When I say "I exist," its content must be different from that when you say "I exist." What makes one subject-self different from another? What makes I into "I"? Where did "I" come from? Where will "I" go after death? Although we may likely never be able to fathom them out completely, we can possibly approach the answers by exploring the necessary features and constituents of subjective-self to enhance our understanding of "I" or the subjective self-concept.

In this article, we argue by reason that the subjective-self is unitary therefore un-duplicable, and, after critically reviewing a couple of thought experiments, further argue that subjective-self, or "I", is more than a blob of brain cells and a stream of memories. Two hypotheses of the third necessary constituent of "I" are presented.

\section{Subjective-Self is Unitary}

From a person's subjective standpoint, there is only one "I" or one myself, although there are many himself's, herself's and yourselves. There are billions of subjective-selves on the earth. But for a particular person, there is just one subjective-self which differentiates him/her from any other one's self. Subjective-self is always singular, while objective "self" can be plural, such as themselves and yourselves. 
It is self-evident that the subjective-self is unitary. Every individual person takes it as a common sense that his/her subjective-self is unitary. No one has ever argued that subjective-self and self-identity can be plural for a mentally normal person. The thesis that electronic robots cannot achieve self-consciousness was derived with the axial phrase "unitary subjective-self” (Wang, 2016).

Notwithstanding that no one has so far cast a doubt about it, uniqueness of subjective-self can be deductively verified, as following.

Thesis Statement 1. Subjective "I" is unitary in a 3-dimensional space at a particular time.

Two individual "selves" coexisting in this world cannot be the same "self", even if the two are very similar (like identical twins) and share the same memories of the past at a time, because the substrates (brains or bodies) of the two selves are independent so they will each experience the current moment uniquely and will have different memories moments later from that time.

Thesis Statement 2. Any human's "I" is unitary along the axis of time in the 4-dimensional space of length-width-height-time.

A baby is born with no memories. Its memories will be built up on his own experiences thereafter, which are different from any person who has ever existed in this world. So, the baby's subjective-self is not the subjective-self of anyone in the past. By the same token, anyone to be born at a future time will not be the self of anyone born before that time, which includes "I" who was born before the future. So, "I" is not the subjective-self of anyone in the future. And "I" is not anyone who currently exists in this world according to Thesis Statement 1. Therefore, any existing "I" is unitary along the axis of time, from the deep past to the deep future, in the 4-dimensional space of length-width-height-time.

With the two Thesis Statements combined, it implies that "I" is unitary or unique in the 4-dimensional space.

\section{Constituents of Subjective-Self}

\section{Is "I" Physical or Psychological?}

What does subjective-self or "I" entail? Some scientists and philosophers endorse the physical theory that it is the brain that originates the subjective-self. As explained by Jim Holt:

My identity as a self is determined by my body; or, more specifically, by my brain, the physical object that is causally responsible for the existence and continuity of my consciousness. On the "I am my brain" view, the actual contents of your stream of consciousness don't matter to your identity. What is all-important is the particular blob of gray meat that is lodged in your skull. You cannot survive the destruction of this blob. (Holt, p. 259)

And the blob of gray meat is so particular and peculiar that "it could not be 'uploaded' into a computer, nor could it be resurrected in some ethereal form” (p. 259).

So when I say "I exist," I am just asserting the existence of a particular functioning brain, according to this perspective. The question "why do I exist?” thus has a purely physical answer: I exist because, at a certain moment in the history of the universe, a certain bunch of atoms happened to come together in a certain way.

Some researchers argued from the psychological perspective. The psychological theory of subjective-self identified the self as nothing more than a focus of memories. "I am my brain" theory seemed insufficient to explain human experience. By the psychological theory, to say "I exist" is just to assert the existence of a certain more or less continuous bundle of memories, perceptions, thoughts, and intentions. What makes me me and you 
you is our distinctive bundles. Without the bundle of memories and perceptions, I would not be "I", and self-awareness would not exist. Newly born babies, for example, do not have any memories, therefore they are not self-aware and their "I's" are not yet there at that time, even though their brains are physically intact and functionable.

We argue that both the physical theory and the psychological theory, as addressed above, are untenable. We next use some thought experiments in literatures to reveal the logical flaws in the above theories about "I" and self-consciousness. Rethinking those thought experiments critically may help conjure up fresh theories about what "I" is.

\section{Kurzweil's and Nagel's Thought Experiments}

Ray Kurzweil (1999) made a thought experiment of copying himself with reverse engineering:

If we scan - let's say myself - and record the exact state, level, and position of every neurotransmitter, synapse, neural connection, and every other relevant detail, and then reinstantiate this massive data base of information (which I estimate at thousands of trillions of bytes) into a neural computer of sufficient capacity, the person that then emerges in the machine will think that he is (and had been) me. He will say 'I grew up in Queens, New York, went to college at MIT, stayed in the Boston area, sold a few artificial intelligence companies, walked into a scanner there, and woke up in the machine here. (p. 42)

Who is the person emerging in the machine? "Objectively,” Kurzweil answered,

the newly built "Ray" is exact me in the eyes of everyone except for me. ... But wait. Is this really me? For one thing, old biological me still exists. I'll still be here in my carbon-cell-based brain. Alas, I will have to sit back and watch the new Ray succeed in endeavors that I could only dream of.

But,

If you then come to me, and say, “Good news, Ray, we have successfully reinstantiated your mind file, so we won’t be needing your old brain anymore," I may suddenly realize the flaw in the "identity from pattern” argument. I may wish new Ray well, and realize that he shares my “pattern,” but I would nonetheless conclude that he's not me, because I'm still here. How could he be me? After all, I would not necessarily know that he even existed. (Kurzweil, 1999, p. 43)

Kurzweil reiterated this thought experiment in his The Singularity is Near (2005) and again asserted that "the copy is not me."

Although the copy shares my pattern, it would be hard to say that the copy is me because I would - or could - still be here. ... Although he would have all my memories and recall having been me, from the point in time of his creation Ray 2 would have his own unique experience, and his reality would begin to diverge from mine. ... If we copy me and then destroy the original, that's the end of me, because as we concluded above, the copy is not me. (p. 384)

For everyone other than Ray, Ray and his copy Ray-2 are identical in terms of body, brain, memory, appearance, intelligence, capability, characters, etc. But for Ray himself, he knows the difference between Ray and Ray-2. He knows that the copy of his brain is not the copy of his subjective-self. That is why Ray does not agree to be destroyed due to the existence of his copy Ray-2. The thought experiment reveals a simple fact that “the 'copy' of Ray's brain is not a genuine copy of Ray in the first place!” (Wang, 2013)

The copy Ray-2 built up with reverse engineering is not Ray when original Ray is alive. What if original Ray dies suddenly after his copy is built? Since Ray-2 is not him before he dies, Ray-2 will still not be Ray after his sudden death because nothing has changed on Ray-2 due to the death of original Ray.

A similar thought experiment was made by Thomas Nagel (1986). He suggested that even if an exact 
physical replica of your brain were created and then stocked with your memories and lodged in a clone of your body, the result would still not be you. Similar to Kurzweil's experiments, Nagel's experiment also suggests that the replica of your brain is not a complete replica of your subjective-self. The replica must have missed something necessary for you to be you.

In fact, the confusion between the original and the replica revealed in these experiments is due to what is addressed in Thesis Statement 1 and Thesis Statement 2. Since any subjective-self is unitary, "I" cannot be copied. Therefore, the physical "replica" of a brain is by no means the subjective-self of the original one. Subjective-self is not just composed of those things in the replica of a brain.

\section{Parfit's Thought Experiment}

Suppose, Parfit (1984) says, all of your brain cells have some defect that would eventually be fatal. Suppose further that a surgeon could replace these brain cells with duplicates that were not defective. The surgeon might do this gradually, in a series of, say, a hundred cell-grafting operations. After the first operation, 99 percent of your original brain would remain. In the middle of the series, half of your brain would consist of original cells and half of duplicates. And just before the final operation, your brain would be a 99 percent replica. Would the self at the end of this series of operations still be you, even though your original brain had been completely destroyed and replaced? And if it ceased to be you, at what point in the series did you suddenly disappear and get replaced by a new life?

This is similar to Kurzweil's thought experiment of gradual replacement by reverse engineering (Kurzweilm, 2005). The thought experiment in Section "Kurzweil's and Nagel's Thought Experiments” has entailed that if a new copy of Ray is built up at a place outside of Ray's body according to the result of scanning Ray's brain, then the copy is not Ray. Even though the two Rays look identical in the eyes of all people, presumably the original Ray himself knows the difference between him and his copy. What if the process of building the new copy of Ray in a few steps? Obviously, as the final result of the process, the copy of Ray will not be the original Ray as far as Ray is alive. That is, subjective-self or "I" cannot be copied and rebuilt at another place to create a new "I" in one step or in multiple steps.

What if your brain is replaced inside your head in multiple steps by the replicas, as suggested in Parfit's thought experiment? Does your subjective-self remain at the end of the gradual replacement process when your original brain is completely replaced by the replica? The brain as the result of the replacement process looks the same as the brain newly built at another place. They both are composed of the replica of your original brain. But their difference is: The former one is built up based on your existing brain while the latter one is built up from scratch.

It has been shown in the last section that the newly built "you" at a place outside of you is not you. What about the result of replacement process in your head? Is it still the original you? We seem to encounter a dilemma: If it is you, then your brain would be identical to the brain built up at a place outside of you which has been proved not you; if it is not you but somebody else, then at which step of the gradual replacement was the original "you" lost and the new guy injected?

The rational answer to this dilemma is: The result of the replacement process is still you. Your subjective-self were not lost in the replacement process. It seems that we here have to admit that "you" is composed of something other than the brain cells, which is unknown to us yet. What are replaced in your head are those brain cells, as we know. Your subjective-self, which is composed of something unknown, has been 
there before the process of replacement. That unknown thing is not touched in the process of replacement. Therefore, you are still you after the process of replacement within your head, no matter whether the replacement is in one step or in multiple steps.

The replica of your brain does not have your subjective-self, because the replica misses something necessary for you to be you, as discussed in Section “Kurzweil's and Nagel's Thought Experiments”. The brain constructed according to the replica, which is an incomplete copy of your brain, therefore does not have your subjective-self. Then, whose subjective-self does that newly built brain have? The rational answer is nobody. That is, it is nobody's subjective-self. The newly built brain is not self-aware at all. That is because subjective-self is unitary, according to Thesis Statements 1 and 2, and anything that is not unitary is not subjective-self. The newly built brain is a replica of your brain. A copy can be further copied, and a replica can be further replicated. Hence, the replica of your brain is not unitary. Since it is not unitary, it is not anyone's subjective-self, according to Statement 2. It does not have any self-identity and is not self-aware at all!

\section{Jim Holt's Experimental Questions and My Tentative Answers}

For the psychological theory about "I", i.e., the self is a bundle of memories and perceptions, Holt (2012) raised a couple of experimental questions. We in this section tentatively give answers to these enlightening questions and discuss their implications.

(1) If you undergo amnesia and lose all your memories, are you still the original you?

My tentative answer:

If you have lost all your memories, you would have lost the necessary condition to be subjective-self of you. You would be like the baby at the time when you were born. You would return to your baby time and would not have the sense of self-awareness. However, even though you have lost the memories about the past, you will still have your experiences in the future and memories about them. You will restart to build up your memories, as you did at your early ages. Amnesia only takes away a necessary condition of your subjective-self. You would remain you when somehow you resume your lost memories or when you have built up sufficient new memories.

(2) If a fiendish neurosurgeon manages to erase all my memories and replace them with your memories, is the original "I" replaced by yours?

My tentative answer:

No, "I" is not replaced by yours. I will remain to be "I". I would have mistaken memories, so mistaken that all I have in my memory are yours instead of mine. But I would not become you. You are still alive there. Your subjective-self is unitary. And you have your future experiences which are definitely different from mine. So, I can't be you. There can't be two you-s now and in the future.

(3) If the neurosurgeon performed the reverse operation on both me and you, would we find ourselves waking up in each other's body?

My tentative answer:

No, I will not be you, and you will not be me, the only mess would be that we both got wrong memories. It is not possible that I would become you and you would become me. If my memories were replaced by yours but your memories were not touched, as we have discussed above, I would not be you, because after we woke up, you would be still you, since your memories were not touched at all. If your memories were changed, it would have nothing to do with my subjective-self. Who I would be after my memories are replaced has nothing 
to do with whether your memories are erased or replaced. Therefore, no matter whether your memories are touched or not, I will not be you. Same arguments apply to show you will not be me after your memories are replaced by mine. So, I will not be you and you will not be me.

Consciousness and memories are a necessary constituent of "I", but they seem not the sufficient constituents of subjective-self, as demonstrated in this thought experiment. Furthermore, the psychological theory implies that the contents of consciousness, such as memories, perceptions, thoughts, and intentions, are only about the past and now. But the self-consciousness should also include those things in the future. Suppose that two individuals were somehow with identical memories, perceptions, thoughts, intentions and experiences about the past in their brains, these two individuals would not be a same "self", because from the next moment their contents of consciousness, as well as memories, would differ from each other since they were independent individuals who would have different experiences and views of the world. Even conjoined twins will have different views and experience in the world: - at least, one would think the other on the left, while the other would think his partner on the right. In this sense, an existing subjective-self, which has both past and future, possesses the memory of the past as well as "memory of the future".

\section{Bernard Williams' Thought Experiment}

A thought experiment was proposed by philosopher Bernard Williams to refute the psychological theory of "I". You are informed that you are going to be tortured tomorrow. Understandably, this makes you fearful. But prior to the torture, you are told, your memories will be wiped out and replaced with my memories. Would you still have reason to fear the torture? If you did, it would mean that, despite your complete psychological makeover as me, it would still be you who endured the pain (Holt, 2012).

Williams here is not accurate to assume "your complete psychological makeover as me" is simply due to my memories in your brain. As we have discussed in the last section, your subjective-self is still there after your memory is replaced by mine, though you now have a completely wrong memory. Your memory is just a part of subjective-yourself, not the complete makeover of you, just like my memory is just a part of subjective-myself, not the complete makeover of $I$.

Memory is a necessary condition for self-awareness. If your memories are completely erased, then you would not be fearful for tomorrow's torture, just like a baby won't. If your memories are replaced with mine, then you would be fearful for tomorrow's torture as far as my memories contain my impressions of pain and torture. But it would be still you, not me, to be tortured, because you only have my memories which are just a part of "I". You cannot be me because I am still here.

It would be clearer if we replaced "to be tortured" with "to be executed" in the William's thought experiment. If your memories were completely erased, then you would have no fear on being executed tomorrow just like a baby would. If your memories were replaced with mine, you would fear tomorrow's execution, as far as my memories contained the understanding of execution and death. And it would be still you, not me, to be executed tomorrow and to die. You only received my memories which were a part of "I". At the time you were executed tomorrow you would have, unfortunately, completely wrong memories, which I would not care. It would be you to be killed. I would be still living after you were executed tomorrow.

\section{"I" Entails More Than a Brain and Memories}

The critics of the four thought experiments above imply convincingly: Subjective-self is not just a blob of brain cells, nor just a stream of memories. It is more than a unity of brain cells as "hardware" and memories as 
"software". There must be some additional constituents for "I" to exist in this world to fully explain the thought experiments.

Thesis Statement 3. To have subjective-self, or "I", in existence, it requires something other than a physical brain which is sophisticated enough to think reflexively and a bundle of memories and perceptions.

Brain cells as hardware and memories and perceptions as software are necessary for subjective-self or "I" to exist but they are not sufficient. Subjective-self must be capable of memorizing the experiences, as well as having certain accumulated memories; it must have a functioning brain sophisticated enough to be able to relate those in memories, to synthesize and abstract those in memories, and to think reflexively. The above four thought experiments tell in clarity that brain cells and memories are not enough for subjective-self to exist. There must be a third constituent of "I". Light entails wave-particle duality. Subjective-self, as an existential phenomenon, looks to be a unity of trinity: brain cells, memories and perceptions, plus a third constituent we do not know yet.

We have observed or derived some characteristics of "I", such as subjectivity, reflexiveness, unitariness, and un-duplicableness, which cannot be represented and explained by the two known constituents, brain cells and memories. Conceptually, both brain cells and memories, for example, do not possess the characteristics of unitariness. A third constituent must be there to embody those peculiar characteristics of "I".

\section{Hypotheses about the Third Constituent of Subjective-Self}

A sophisticated brain and a bundle of memories are constituents of "I", but they are not the only constituents of "I" as addressed in Thesis Statement 3. There must be other necessary constituents for subjective-self, or "I", to exist. Let's put such an unknown constituent as constituent $X$.

Without appealing for a divine power, we have come up with two hypotheses about the third constituent $\mathrm{X}$ of "I".

\section{Hypothesis 1.}

The third constituent X of "I" is something in our 3-dimensional world, but it is not yet known by us. Examples of such things are dark matter and dark energy.

That is, subjective "I" is composed of the known ordinary matter as well as unknown matter such as dark matter or dark energy. As humans, we are able to see those parts which are composed of ordinary matter, such as body, brain, and cells. But for those parts that are composed of unknown matter, such as perception and self-consciousness, one can only see or feel his own. One cannot see or feel another's consciousness and perceptions.

Death means that those parts composed of ordinary matter stop working. As for those composed of unknown matter, such as self-consciousness, we do not know whether they stop working or where they go after organic death. We simply have no idea yet about the matter or energy that is unknown. What we are aware of is just the existence of dark matter and dark energy, and no more than this. What are the laws relating to dark matter and dark energy? Are there any more beyond them? There are many such challenging questions for us to answer for the purpose of understanding what "I" am and where "I" go after death.

\section{Hypothesis 2.}

The third constituent $\mathrm{X}$ is something in higher dimensional space, higher than our 4-dimensional length-width-height-time space.

In general, the existence in the higher dimensional space is not perceived by those beings in the lower 
space. In a 2-dimensional space, everything has just a length and a width but has no height. If we lived on such a flat (or curved) surface, we could just see and perceive whatever on this surface, and we would have no way to see and perceive anything hanging above the surface, unless it left some vestige on our surface such as its shadow, or it exerted some influence on something on the surface such as gravity.

Moreover, a same thing can be viewed differently from spaces with different dimensions. For example, a polygonal line in a 2-dimensional space is associated with a non-linear equation. If we increase number of variable x's properly, that polygonal line could be possibly represented by a linear equation. We use such a conversion in multiple regression analysis in statistics. This example shows that a non-linear line in a 2-dimensional space can become linear in higher dimensional space. If someone said that a polygonal line was linear, we would certainly take it as an absurdity when we stick to 2-dimensional space. But once we came into a higher dimensional space, that assertion could become true.

Death for us means vanishing from the space we live in. Suppose we lived in a 2-dimensional surface. If one left this surface and flew into the 3-dimensional space, then we would not be able to see him, and he would vanish from us. Then, for us living on the 2-dimensional surface, we would say, "He died". But in fact he had just suspended away from our surface and entered the 3-dimensional space. This hypothesis assumes that our physical brain and self-consciousness are not in the same dimensional space. We are pretty sure that our brain is in a 3-dimensional space with length-width-height. If time is added in, then we say that we live in a 4-dimensional space. That is the limit of our thinking. We cannot imagine what things are like in a 5-dimensional space, just like a 2-dimensional being cannot fathom out what height means. If self-consciousness were something in a 5-dimensional space, then that "I" might be something coming down to the lower dimensional space for a contingent visit. Death would be the end of that visit.

\section{Summary and Additional Discussions}

(1) The kernel of human's consciousness is self-consciousness, which is also most subtle and mysterious part of consciousness. The issue about where a person goes after death is actually an issue about what the subjective-self is.

(2) There is no contention on the theory that the nerve system and brain are where the reasoning capability and lower level consciousness come from. For lower level consciousness we refer to those that are non-reflexive, such as hunger, thirst, sexual desire, pain, and fatigue. If the nervous system and brain stop working, the reasoning capacity and lower level consciousness stop as well. Higher level consciousness is self-reflexively reliant, which cannot be fully explained by the nervous system and brain, as shown in the thought experiments of Ray Kurzweil and Derek Parfit.

(3) Our analyses on the four thought experiments have revealed that, logically, there must be a third constituent X to join the physical brain and psychological memories to form subjective self. That is, "I" is trinity of a physical brain, a stream of memories, and constituent $\mathrm{X}$ in unity. Two subjective-selves are same only if all the three constituents are same.

(4) We have proposed two hypotheses about the third constituent X: it is something unknown for us yet like dark matter, or it is something in a higher dimensional space. They are just hypotheses. There have been no arguments or thought experiments yet showing the logical impossibility of the hypotheses. Anything is possible if it does not cause logical contradictions.

(5) Where does self-consciousness go after death? For subjective-self which is a trinity of three 
constituents, death means the end of physical brain and psychological perception. Where the third constituent goes after the body is dead remains a mystery, which is currently beyond the humble knowledge we have had.

\section{References}

Becker, E. (1973). The denial of death. New York, NY: The Free Press.

Holt, J. (2012). Why does the world exist? - an existential detective story. New York-London: Liveright Publishing Corporation. Kurzweil, R. (1999). The age of spiritual machines—when computers exceed human intelligence. New York: Penguin Books.

Kurzweil, R. (2005). The singularity is near-when humans transcend biology. New York: Penguin Books.

Kurzweil, R. (2013). How to create a mind - the secret of human thought revealed. New York: Penguin Books.

Nagel, T. (1986). View from nowhere. New York: Oxford University Press.

Parfit, D. (1984). Liberating and consoling. Reasons and Persons. Oxford: Oxford University Press.

Penrose, R. (1999). The emperor's new mind. Oxford: Oxford University Press.

Precht, R. (2011). Who am I? And if so, how many? A philosophical journey. New York, NY: The Random House Publishing Group.

Wang, J. (2013). On the limit of machine intelligence. International Journal of Intelligence Science, 3, 170-175.

Wang, J. (2016). Is subjective self-identity programmable? International Journal of Artificial Intelligence, 14(1), 41-52. 